EESTI NSV TEADUSTE AKADEEMIA TOIMETISED 1954. III kd., nr. 1

ИЗВЕСТИЯ АКАДЕМИИ НАУК ЭСТОНСКОИ ССР 1954. Том III, № 1

\title{
ALGEBRALISTE VÕRRANDITE NOMOGRAAFILISEST LAHENDAMISEST
}

A. HUMAL,

Eesti NSV Teaduste Akadeemia tegevliige

Võrrandi $a_{0} x^{n}+a_{1} x^{n-1}+\ldots+a_{n-1} x+a_{n}=0$ lahendamist (reaalarvuliste $a_{0}, a_{1}, \ldots, a_{n}$ puhul) läheb teatavasti tähtsa lülina vaja väga mitmesugustes matemaatilistes protsessides. Mõnesuguste rakenduste jaoks ei piisa ainult reaalsete lahendite leidmisest; vajadus algebralise võrrandi kompleksarvulisi lahendeid leida (nimelt reaalsete $a_{0}, a_{1}, \ldots, a_{n}$ juhui) esineb näiteks diferentsiaalvõrrandi karakteristlike arvude otsimịsel. Algebralise võrrandi lahendite arvutamine ei ole raske ülesanne, kui $n<3$; ka siis, kui $n=3$, osutub lahendite otsene arvutamine sellekohase tabeli ( ${ }^{1}$ ) abil veel võrdlemisi hõlpsaks; palju raskem aga on lahendeid arvutada, kui $n=4$ : neljandaastmelise vorrrandi algebraline lahendamine toimub küll kuupvõrrandi lahendamise kaudu, kuid sel viisil lahendite arvutamiseks kulub üsna palju tööd. Viienda- ja kõrgemaastmeliste võrrandite puhul on teatavasti juba võimatu lahendeid algebraliselt avaldada üldandmetest $a_{0}, a_{1}, \ldots, a_{n}$ ning järelikult ei saa siis lahendite otsene arvutamine üldiselt enam küsimusse tulla, vaid jääb üle kasutada ainult ligikaudse lahendamise võtteid.

Võrrandite ligikaudse lahendamise võtteid võib jaotada kahte liiki: ühed võimaldavad lahendite lähisväärtusi leida teatava piiratud täpsusega, teised aga ainult parandavad lahendi lähisväärtust mistahes täpsuseni (eeldades, et on teada mingi lähisväärtus, mida parandada). Esimesi võib seega nimetada võrrandite ligikaudse lahendamise põhivõteteks ja teisi abivõteteks. On arusaadav, et kui põhivõtte täpsus osutub küllaldaseks, siis abivõtteid vaja ei lähe. Abivõtete iseloomustamiseks võib üldiselt öelda, et nad sisaldavad võrdlemisi lihtsat numbrilist arvutamist ja viivad tavaliselt hõlpsasti sihile. Seevastu numbrilisi põhivõtteid võrrandite ligikaudseks lahendamiseks võib iseloomustada üldiselt kui raskepäraseid võtteid, mis nõuavad sageli ettenägematult palju arvutamistööd.

Võrrandite ligikaudse lahendamise graafilistest põhivõtetest väärivad esikohale tõstmist nn. nomograafilised võ̃tted. Selle nimetuse alla võetakse kokku kõik need graafilised lahendamisvõtted, mis on kirjeldatavad järgmiselt: teatava ülesandetüübi jaoks valmistatakse joonis - nomogramm mis võimaldab antud tüüpi kuuluva ülesande lahendit ära lugeda (vastavalt ülesande individuaalsetele andmetele), ilma et selleks vaja oleks midagi juurde joonestada. Nomogrammi kasutamisel võib küll vaja olla kas sirgutõmmatud niiti (või selle asemel joonlaua äärt), mõõtesirklit või joonestamiskolmnurka, kuid ainult punktide kätteleidmiseks. Olgu tähendatud, et mõnesuguste ülesannete lahendamisel esineb valmis nomogrammina 
lihtsalt leht millimeetripaberit, näiteks ruutvõrrandi reaalsete lahendite leidmisel $\left({ }^{2}\right)$.

Alljärgnevalt antakse ülevaade neljanda- ja viiendaastmeliste võrrandite lahendamise nomograafilistest võtetest ja võrreldakse neid rakendamisulatuse poolest. Ettevalmistavalt jääb märkida, et võrrandit $a_{0} x^{4}+a_{1} x^{3}+a_{2} x^{2}+a_{3} x+a_{4}=0$ (milles muidugi $a_{0} \neq 0$ ) saab teatavasti alati lihtsustada üleminekuga uuele otsitavale $X$, võttes $x=X-\frac{a_{1}}{4 a_{0}}$; uue võrrandi

$$
X^{4}+p X^{2}+q X+r=0
$$

konstantide $p, q$ ja $r$ arvutamist on kohane sooritada Horneri skeemi järgi $\left({ }^{3}\right)$. Samuti saab võrrandit $a_{0} x^{5}+a_{1} x^{4}+a_{2} x^{3}+a_{3} x^{2}+a_{4} x+a_{5}=0$ lihtsustada teisendusega $x=X-\frac{a_{1}}{5 a_{0}}$ võrrandiks

$$
X^{5}+p X^{3}+q X^{2}+r X+s=0 .
$$

Järelikult võib nomograafiliste lahendamisvõtete käsitlemisel piirduda niisuguste lihtsustatud võrranditega.

\section{Nomogrammid neljandaastmelise võrrandi reaalsete lahendite leidmiseks}

1. Võrrandi $x^{4}+p x^{2}+q x+r=0$ geomeetriliseks lahendamiseks selgub kõige hõlpsam võimalus järgmiselt: kui võtta abitundmatu $y$ nii, et $y=x^{2}$, siis saab võrrandit ümber kirjutada ringjoone võrrandiks

$$
x^{2}+y^{2}+q x+(p-1) y+r=0 ;
$$

järelikult on võrrandi $x^{4}+p x^{2}+q x+r=0$ lahendid parabooli $y=x^{2}$ ja ringjoone $x^{2}+y^{2}+q x+(p-1) y+r=0$ lõikepunktide abstsissid $\left({ }^{4}\right)$. Lõikepunktide leidmiseks piisab ainult parabooli joonestamisest, kuna ringjoont saab kasutada ilma joonestamata: teades tema keskpunkti ja raadiust saab mõõtesirkliga kohe näidata punktid, kus ta parabooli lõikab, ja nende abstsissid kindlaks teha. Seega osutub neljandaastmelise võrrandi nomogrammiks tavaline koordinaadivõrk ühes parabooliga (joon. 1); iga individuaalse võrrandi jaoks leitakse (antud $p, q$ ja $r$ väärtuste järgi) vastava ringjoone keskpunkt $\left(-\frac{q}{2} ; \frac{1-p}{2}\right)$ ja raadius $\sqrt{\left(\frac{q}{2}\right)^{2}+\left(\frac{1-p}{2}\right)^{2}-r}$ ning saadakse mõõtesirkli abil punktid, kus ringjoon parabooli lõikab. * Koordinaadivõrk võimaldab niihästi ringjoone keskpunkti kätteleidmist kui ka lõikepunktide abstsisside äralugemist.

Võib juhtuda, et ringjoone keskpunkt $\left(-\frac{q}{2} ; \frac{1-p}{2}\right)$ ei satu joonise piirkonda või raadius $\sqrt{\left(\frac{q}{2}\right)^{2}+\left(\frac{1-p}{2}\right)^{2}-r}$ osutub kas nii suureks, et ringjoone ja parabooli lõikepunktid ei mahu tehtud joonisele, või nii väikseks, et lõikepunktide abstsisse ei saa paraja täpsusega kindlaks teha

* Sama nomogramm võimaldab lahendada ka kuupvōrrandit $x^{3}+p x+q=0$, sest selle lahenditeks on kõik need võrrandi $x^{4}+p x^{2}+q x=0$ lahendid, mis erinevad nullist; pealegi hōlbustub nüüd võtte rakendamine selle poolest, et ringjoon $x^{2}+y^{2}+q x+$ $+(p-1) y=0$ läbib koordinaatide alguspunkti ja seega pole tema raadiust vaja arvutada. 


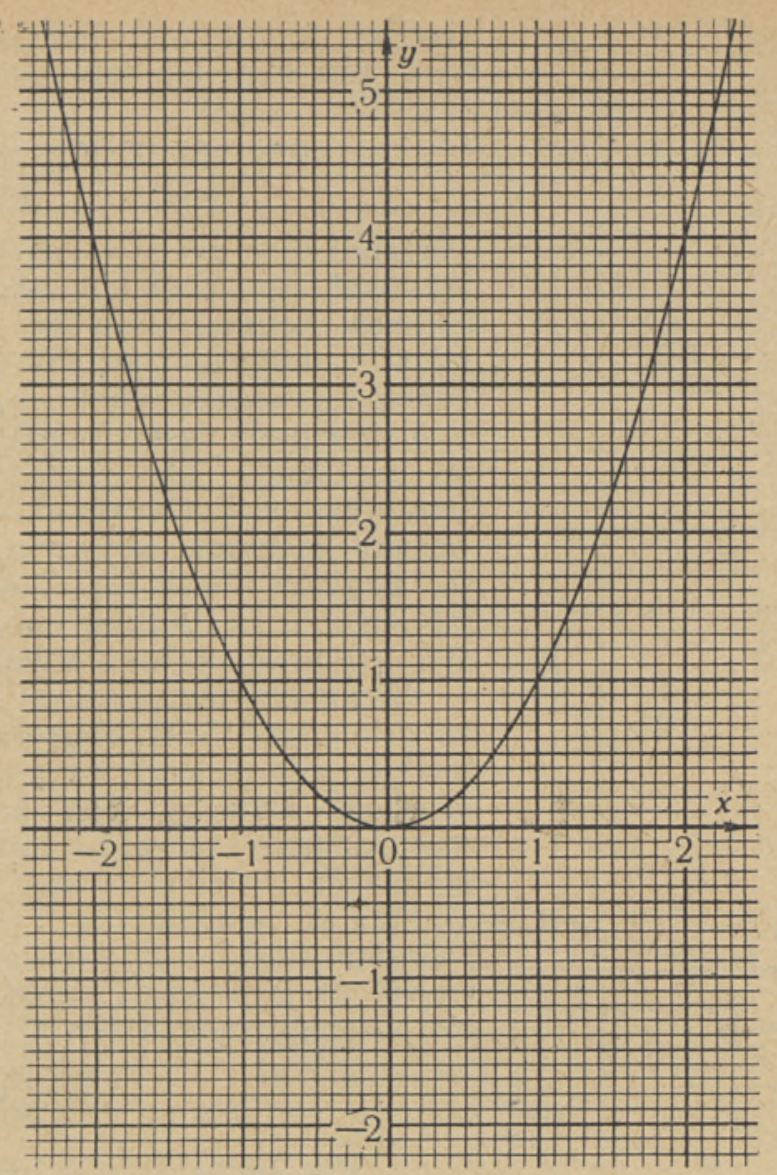

Joon. 1 .

(eriti kui ringjoone keskpunkt on koordinaatide alguspunkti läheduses). Kõigil neil juhtudel kõrvaldab raskused lihtne teisendus

$$
x=c \mathrm{x}
$$

vastavalt sobiva konstandi $c$ valikul. Uue võrrandi

$$
\mathrm{x}^{4}+\frac{p}{c^{2}} \mathrm{x}^{2}+\frac{q}{c^{3}} \mathrm{x}+\frac{r}{c^{4}}=0
$$

jaokș saab nimelt $c$ väärtuse nii võtta, et vastav ringjoon osutub olemasolevale nomogrammile parajaks (pealegi võib valikul piirduda arvutuseks soodsamate $c$ väärtustega, nagu $2, \frac{1}{2}, 4, \frac{1}{4}, 5, \frac{1}{5}, 10, \frac{1}{10}$ ).

2. Uusi võimalusi võrrandi $x^{4}+p x^{2}+q x+r=0$ nomograafiliseks lahendamiseks tekib teisendusega $x=c x$, kui konstandi $c$ väärtuseks võetakse $\sqrt[3]{q}$. (Juhtum $q=0$, mis siis käsitlusest välja jääb, ei paku siinkohal huvi, sest võrrand $x^{4}+p x^{2}+r=0$ osutub ruutvõrrandiks otsitavaga $x^{2}$ ja tema lahendite otsene arvutamine läheb seetõttu hõlpsasti.) Otsitava $x$ jaoks saadud võrrand

$$
\mathrm{x}^{4}+\frac{p}{\sqrt[3]{q^{2}}} \mathrm{x}^{2}+\mathrm{x}+\frac{r}{q \sqrt[3]{q}}=0
$$




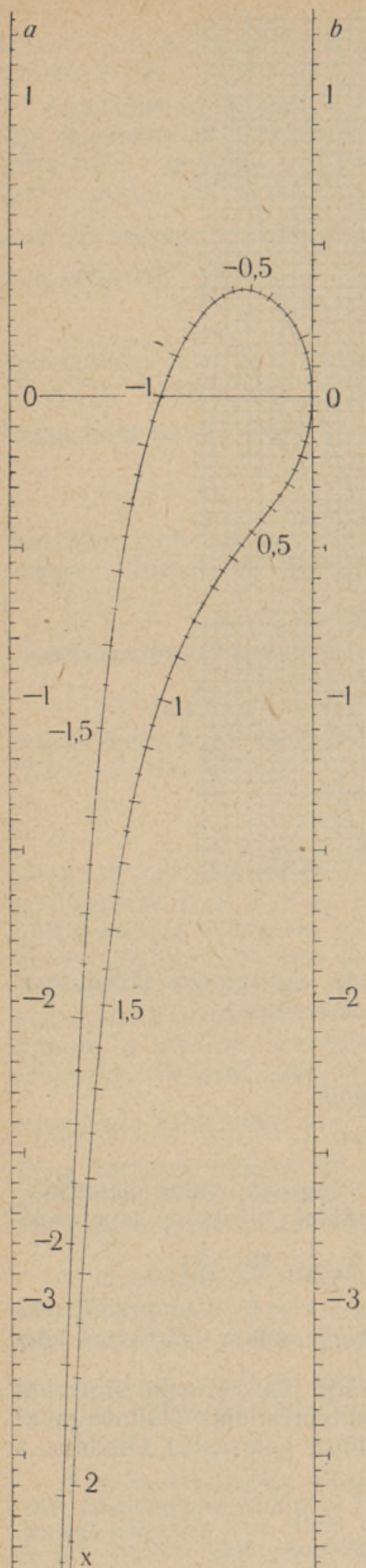

Joon. 2 . sisaldab ainult kaht individuaalset konstanti, mis olgu lühidalt tähistatud $a$ ja $b$ :

$$
a=\frac{p}{\sqrt[3]{q^{2}}}, \quad b=\frac{r}{q \sqrt[3]{q}} .
$$

Võrrandi $\mathrm{x}^{4}+a \mathrm{x}^{2}+\mathrm{x}+b=0$ lahendamiseks saab aga valmistada nomogrammi, mis koosneb kolmest skaalast (joon. 2) ja mida kasutatakse järgmiselt: võetakse $a$ väärtusele vastav punkt vasakul skaalal ja $b$ väärtusele vastav punkt paremal skaalal, asetatakse läbi nende punktide sirgjoon (kas sirgutõmmatud niit või läbipaistva joonlaua serv), vaadatakse, kus see sirgjoon lõikab keskel asetsevat kõverat skaalat, ja loetakse sealt lõikepunktidele vastavad otsitava $\mathrm{x}$ väärtused.

Niisuguse nomogrammi valmistamisel on peamiseks tööks kõvera skaala joonestamine, sest $a$-skaala ja $b$-skaala on ühtlased ja nendeks saab kasutada millimeetripaberil olevaid võrgujooni ühes jaotustega. Keskel olev kõver skaala (x-skaala) aga saadakse järgmiselt $\left({ }^{5}\right)$ : koordinaadistikus, kus $a$-skaala iga punkt on $(0 ; a)$ ja $b$-skaala punkt $(1 ; b)$, koosneb $\mathrm{x}$-skaala * punktidest

$$
\left(\frac{1}{1+x^{2}} ;-\frac{x+x^{4}}{1+x^{2}}\right) \text {. }
$$

3. Võrrandile $x^{4}+a x^{2}+x+b=0$ saab valmistada ka võrknomogrammi (joon. 3): $a$ loetakse abstsissiks ja $b$ ordinaadiks, suurust $\mathrm{x}$ aga kasutatakse kui parameetrit, mille iga üksik väärtus mää$\mathrm{rab}$ joonisel sirgjoone, sest võrrand $\mathrm{x}^{4}+a \mathrm{x}^{2}+\mathrm{x}+b=0$ on koordinaatide $a$ ja $b$ suhtes lineaarne. Võrknomogrammil vastab teatavasti antud võrrandile tema individuaalsete $a$ ja $b$ väärtustega määratud punkt $(a ; b)$ ning võrrandi lahendi-

* Otsitavad x-skaala punktide koordinaatide avaldised $f(x)$ ja $g(x)$ on määratud kahe endastmõistetava tingimusega: 1) punktid $(0 ; a),(1 ; b)$ ja $(f(x) ; g(x))$ peavad asetsema ühisel sirgel seega

$$
\frac{g(\mathrm{x})-a}{f(\mathrm{x})-0}=\frac{b-a}{1-0}
$$

ehk $a(1-f(\mathrm{x}))+b f(\mathrm{x})-g(\mathrm{x})=0 ; \quad 2)$ saadud vōrrandiga peab samaväărne olema vōrrand $\mathrm{x}^{4}+a \mathrm{x}^{2}+\mathrm{x}+b=0$; järelikult

$\frac{1-f(\mathrm{x})}{\mathrm{x}^{2}}=\frac{f(\mathrm{x})}{1}=-\frac{g \mathrm{x})}{\mathrm{x}^{4}+\mathrm{x}}$, millest $f(\mathrm{x})=\frac{1}{1+\mathrm{x}^{2}}$ ja $g(x)=-\frac{x^{4}+x}{1+x^{2}}$. 


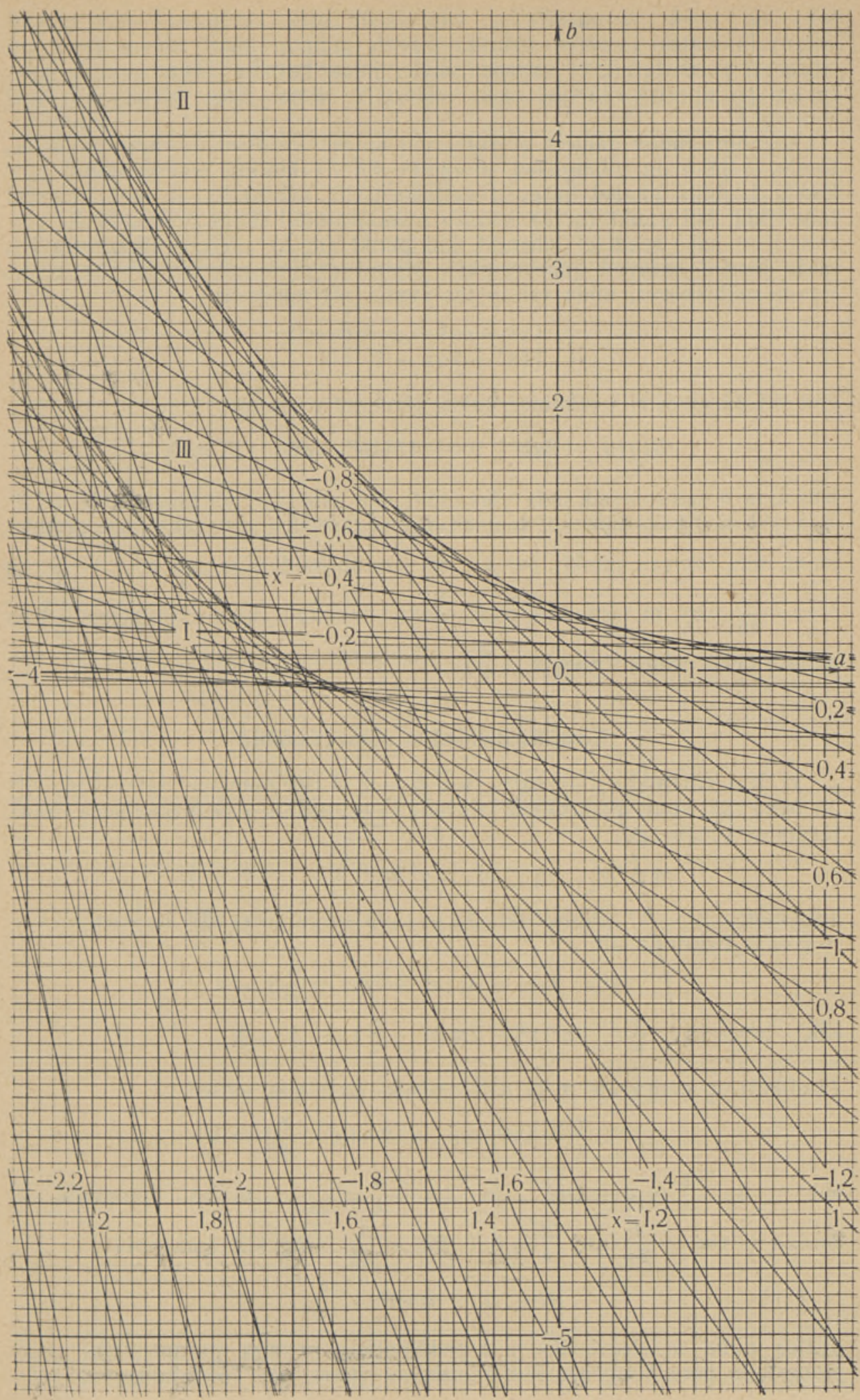

Joon. 3 . 
teks on need parameetri $x$ väärtused, mis kuuluvad seda punkti $(a ; b)$ läbivatele joontele. (Muidugi peab nomogrammil olema jooni nii tihedasti joonestatud, et vahepealsetele, joonestamata jäetud joontele kuuluvaid parameetri väärtusi oleks võimalik silma järgi küllalt kindlasti hinnata.)

Nomogrammist nähtub, et võrrandil on neli reaalset lahendit, kui konstandid $a$ ja $b$ on niisugused, et punkt $(a ; b)$ kuulub nomogrammil piirkonda I, mida jooned katavad neljakordselt; võrrandil ei ole reaalseid lahendeid, kui punkt $(a ; b)$ kuulub nomogrammil tühja piirkonda II; võrrandil on kaks reaalset lahendit, kui punkt $(a ; b)$ asetseb piirkonnas III, mida jooned katavad kahekordselt. Mainitud piirkondi eraldab üksteisest joonte mähiskõver, mida esitab teatavasti võrrandipaar

$$
\left\{\begin{array}{l}
x^{4}+a x^{2}+x+b=0 \\
4 x^{3}+2 a x+1=0
\end{array}\right.
$$

ehk siit parameetri $\mathrm{x}$ elimineerimisel järelduv võrrand

$$
16 a b\left(a^{3}-8 a b+9\right)+4\left(64 b^{3}-a^{3}\right)-27=0 .
$$

Kui $a$ ja $b$ rahuldavad seda võrrandit, siis osutuvad võrrandi $x^{4}+a x^{2}+$ $+\mathrm{x}+b=0$ kaks lahendit teineteisega võrdseteks, sest kaks nomogrammi joont, mis läbivad punkti $(a ; b)$, on siis ühtinud. Kui aga $a=-\frac{3}{2}$ ja $b=-\frac{3}{16}$, siis on võrrandil kolm võrdset lahendit (kõik väärtusega $\frac{1}{2}$ ) ja neljast neist erinev (nimelt $-\frac{3}{2}$ ).

\section{Komplekslahendite nomogrammid}

4. Kui võrrandil $x^{4}+a x^{2}+x+b=0$ ei ole reaalseid lahendeid, siis on tema neli kompleksarvulist lahendit (konstantide $a$ ja $b$ reaalsuse tõttu) järgmise koostisega:

$$
m+h \mathrm{i}, \quad m-h \mathrm{i}, \quad-m+k \mathrm{i}, \quad-m-k \mathrm{i} .
$$

Tähistades $m^{2}+h^{2}$ lühidalt tähega $n$, saab seega võrrandit $\mathrm{x}^{4}+a \mathrm{x}^{2}+\mathrm{x}+$ $+b=0$ kirjutada nii:

$$
\left(\mathrm{x}^{2}-2 m \mathrm{x}+n\right)\left(\mathrm{x}^{2}+2 m \mathrm{x}+\frac{b}{n}\right)=0
$$

ehk $\quad x^{4}+\left(n+\frac{b}{n}-4 m^{2}\right) x^{2}+2 m\left(n-\frac{b}{n}\right) x+b=0$.

Järelikult on otsitavate $m$ ja $n$ leidmiseks kasutada seosed

$$
n+\frac{b}{n}-4 m^{2}=a \text { ja } 2 m\left(n-\frac{b}{n}\right)=1
$$

ehk $n+\frac{b}{n}=a+4 m^{2} \quad$ ja $n-\frac{b}{n}=\frac{1}{2 m}$, millest järeldub, et $2 n=a+4 m^{2}+\frac{1}{2 m}$ ja $\frac{2 b}{n}=a+4 m^{2}-\frac{1}{2 m}$ ning siit omakorda

$$
4 b=\left(a+4 m^{2}\right)^{2}-\frac{1}{4 m^{2}} .
$$

Võttes nüüd $a$ abstsissiks ja $b$ ordinaadiks, $m$ aga parameetriks, saab joonestada pere kongruentseid paraboole (joon. 4). Tööd hõlbustab asja- 


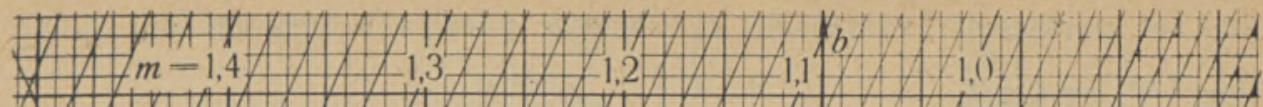

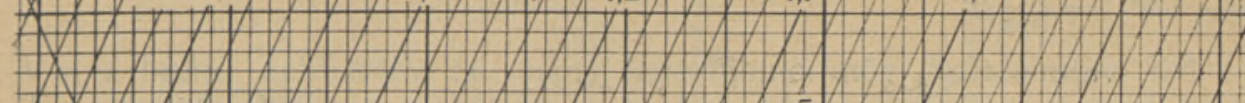

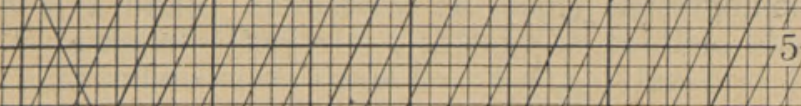
$\underbrace{(2)}$

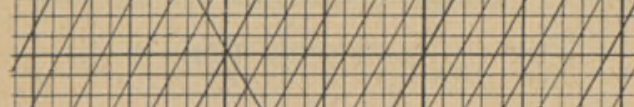
in $1 \times 1 \times 12$ $\left(1 / 1 \times 11^{1} / 1^{3}\right.$

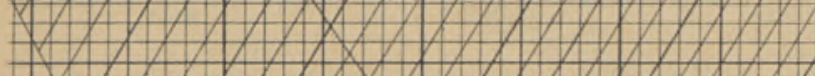
-1/1/1)

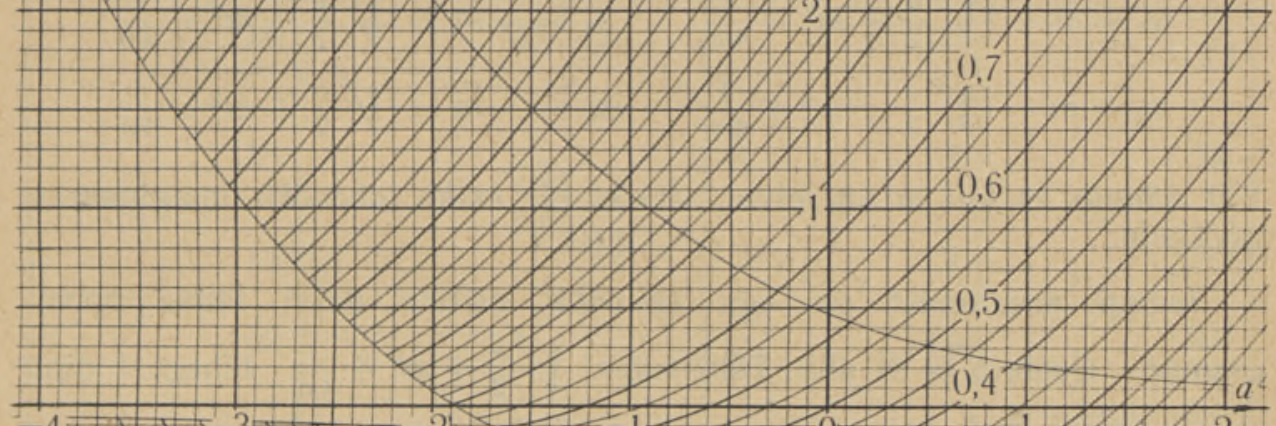

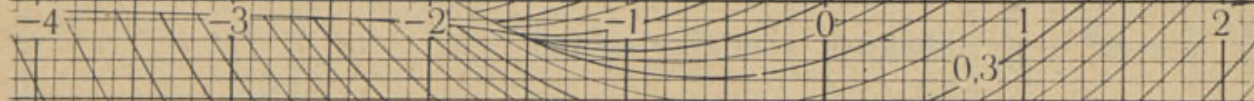
| 
olu, et parameetri väärtusele $m$ vastava parabooli haripunktiks osutub $\left(-4 m^{2} ;-\frac{1}{16 m^{2}}\right)$.

Nii valmistatud võrknomogramm (joon. 4) võimaldab antud $a$ ja $b$ järgi tuntud viisil ära lugeda otsitava $m$ väärtust; järelikult saadakse sellelt nomogrammilt võrrandi $x^{4}+a x^{2}+x+b=0$ komplekslahendite reaalosad.

5. Lahendite imaginaarosad on võrdlemisi hõlpsasti otseselt arvutatavad, kui andmeteks võetakse peale $a$ ja $b$ ka leitud $m$ (mida võib enne veel mingi parandusvõtte abil täpsustada, kasutades selleks seost $\left.\left({ }^{*}\right)\right)$. Seetõttu, et võrrandi $\mathrm{x}^{4}+a \mathrm{x}^{2}+\mathrm{x}+b=0$ komplekslahenditeks on ruutvõrrandite $\mathrm{x}^{2}-2 m \mathrm{x}+n=0 \quad$ ja $\mathrm{x}^{2}+2 m \mathrm{x}+\frac{b}{n}=0$ ehk (kui $n$ ja $\frac{b}{n}$ avaldada leitud $m$ abil)

$$
\mathrm{X}^{2}-2 m \mathrm{x}+\frac{a}{2}+2 m^{2}+\frac{1}{4 m}=0 \text { ja } \mathrm{x}^{2}+2 m \mathrm{x}+\frac{a}{2}+2 m^{2}-\frac{1}{4 m}=0
$$

lahendid, avalduvad nad järgmiselt:

$$
\begin{array}{ll}
\mathrm{x}_{1}=m+\mathrm{i} \sqrt{\frac{a}{2}+m^{2}+\frac{1}{4 m}} & \mathrm{x}_{3}=-m+\mathrm{i} \sqrt{\frac{a}{2}+m^{2}-\frac{1}{4 m}} \\
\mathrm{x}_{2}=m-\mathrm{i} \sqrt{\frac{a}{2}+m^{2}+\frac{1}{4 m}} & \mathrm{x}_{4}=-m-\mathrm{i} \sqrt{\frac{a}{2}+m^{2}-\frac{1}{4 m}}
\end{array}
$$

Siit nähtub, et kui $m$ on leitud, siis ei ole raske lahendite imaginaarosi arvutada.

Sedagi arvutamist on aga võimalik vältida paari lihtsa nomogrammi (joon. 5 ja 6) abil. Tähistades $\sqrt{\frac{a}{2}+m^{2}+\frac{1}{4 m}}$ tähega $h$ ning $\sqrt{\frac{a}{2}+m^{2}-\frac{1}{4 m}}$ tähega $k$, saadakse seosed

$$
\frac{a}{2}+m^{2}+\frac{1}{4 m}=h^{2} \quad \text { ja } \quad \frac{a}{2}+m^{2}-\frac{1}{4 m}=k^{2} ;
$$

mõlemale saab valmistada skaaladest koosneva nomogrammi: ühel (joon. 5) on vasakpoolne skaala moodustatud punktidest $\left(0 ; \frac{a}{2}\right)$, parempoolne punktidest $\left(1 ; m^{2}+\frac{1}{4 m}\right)$ ja keskel olev skaala punktidest $\left(\frac{1}{2} ; \frac{h^{2}}{2}\right)$, kuna teisel (joon. 6) koosneb vasakpoolne skaala samuti punktidest $\left(0 ; \frac{a}{2}\right)$, parempoolne aga punktidest $\left(1 ; m^{2}-\frac{1}{4 m}\right)$ ja keskmine punktidest $\left(\frac{1}{2} ; \frac{k^{2}}{2}\right)$. Niisuguste nomogrammide kasutamisviisi on kirjeldatud juba joonise 2 puhul.

6. Võrrandi $x^{4}+a x^{2}+x+b=0$ komplekslahendite imaginaarosi on võimalik nomograafiliselt leida ka omaette, ilma reaalosade eelneva leidmiseta. Selleks vajalikku võrknomogrammi (joon. 7) on aga märksa raskem valmistada kui eelmisi nomogramme, sest siin on kõik jooned kujult väga erinevad. Uks pere kõverjooni ( $h$-jooned) läheb vaja selleks, 


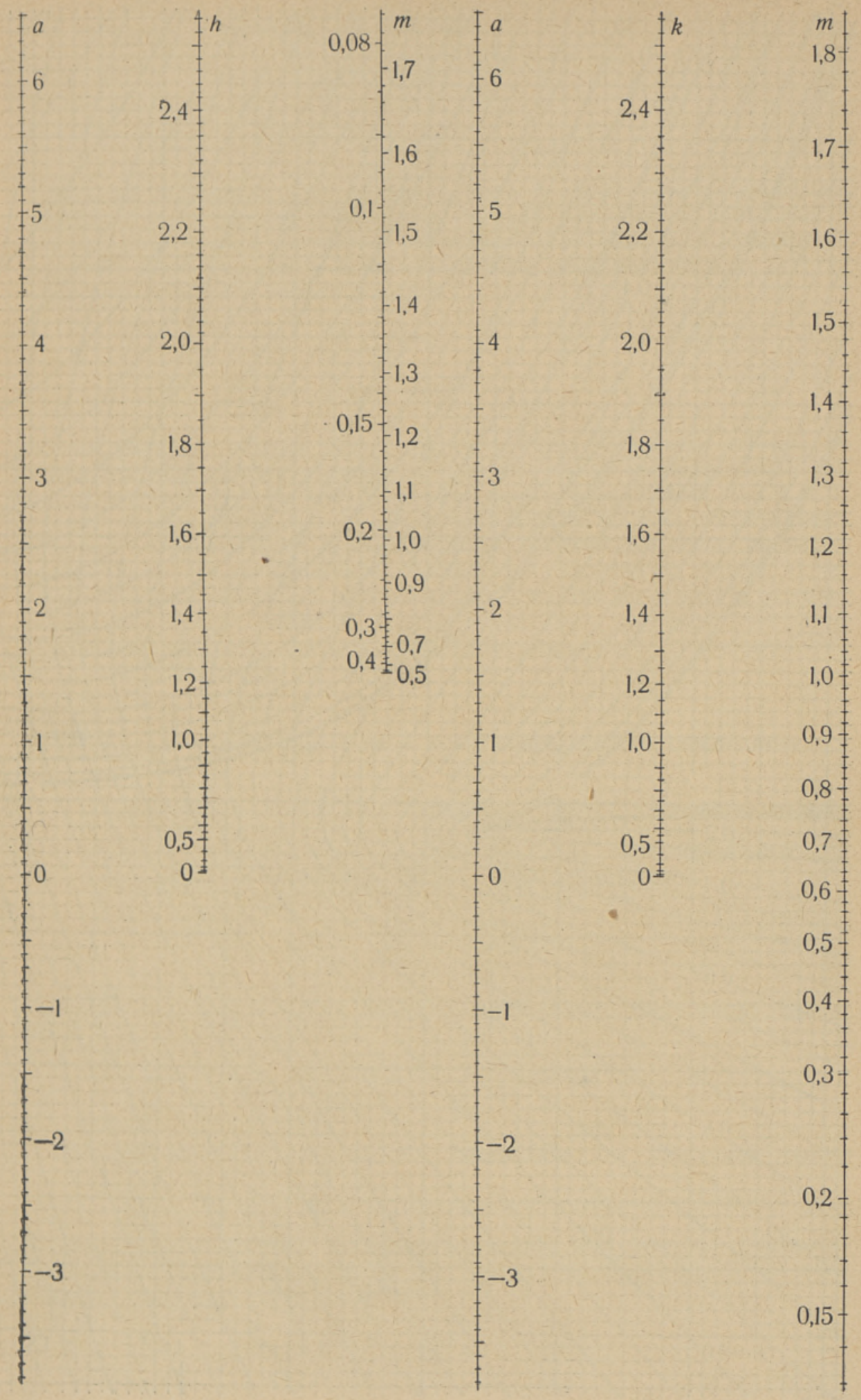

Joon. 5 .

Joon. 6 . 


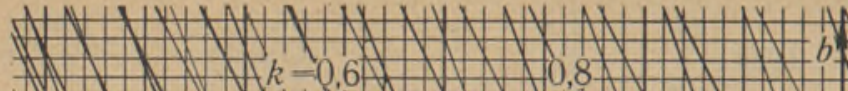

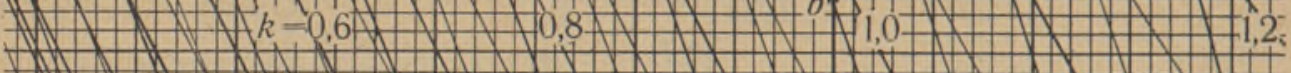

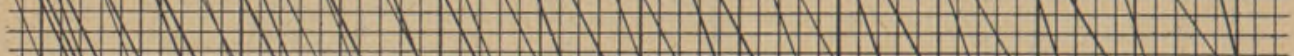
7 N $N$ N 7 N

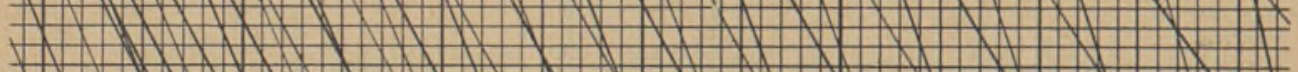
$7 N$ N 5 N

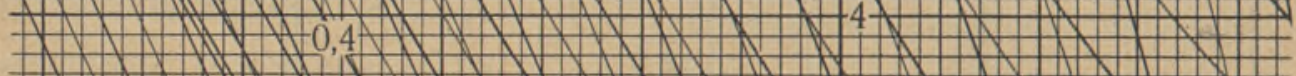
$+1 N$ N

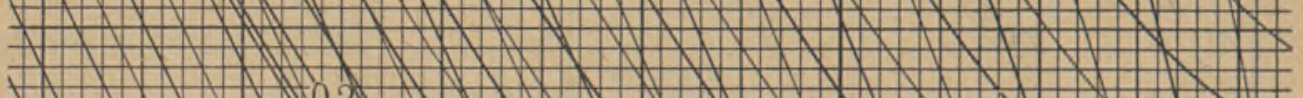
F 140,2 5 P N (1)

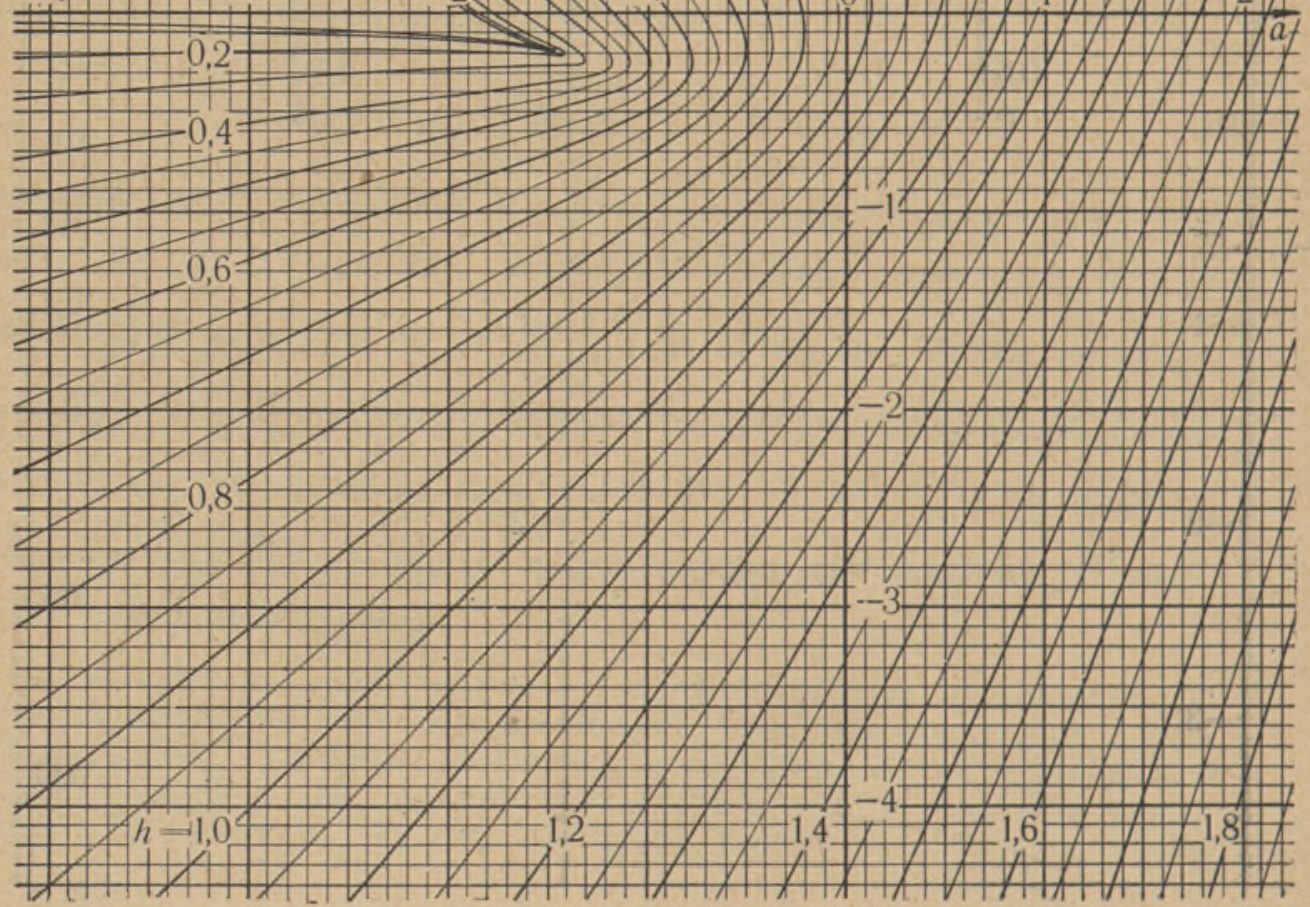


et saada andmete $a$ ja $b$ järgi kahe komplekslahendi imaginaarosad $h \mathrm{i}$ ja - hi; selle pere võrrandipaar on nähtavasti

$$
\left\{\begin{array}{l}
a=2 h^{2}-2 m^{2}-\frac{1}{2 m} \\
b=\frac{1}{4}\left(a+4 m^{2}\right)^{2}-\frac{1}{16 m^{2}},
\end{array}\right.
$$

milles $a$ on abstsiss ja $b$ on ordinaat, kuna $h$ esineb pere parameetrina (abisuurust $m$ ei tarvitse elimineerida, ta jääb kasutamisele igal üksikul joonel punktist punkti muutuva parameetrina). Teine pere kõverjooni ( $k$-jooned) läheb vaja teiste komplekslahendite imaginaarosade $k \mathrm{i}$ ja $-k \mathrm{i}$ leidmiseks; selle pere võrrandipaar on

$$
\left\{\begin{array}{l}
a=2 k^{2}-2 m^{2}+\frac{1}{2 m} \\
b=\frac{1}{4}\left(a+4 m^{2}\right)^{2}-\frac{1}{16 m^{2}}
\end{array}\right.
$$

Mōlema pere joonte jaoks saab punktide leidmist hõlbustada sel teel, et abijoontena kasutatakse paraboole jooniselt 4 ja piirkondadevahelist kõverat jooniselt 3 (selle kõvera üks osa koosneb punktidest, kus $h=0$, ja teine osa punktidest, kus $k=0$ ). Nimelt nähtub mõlema võrrandipaari esimestest võrranditest, et igalt abisuuruse $m$ üksikväärtusele vastavalt paraboolilt on lihtne kätte leida punkte, kus parameetril $h$ (või $k$ ) on teatavad valitud väärtused, sest niisuguste punktide abstsissid $a$ ei erine milleski muus kui liikme $2 h^{2}$ (või $2 k^{2}$ ) väärtuses; järelikult võib need punktîd paraboolil ära märkida abstsisside järgi, alates tuntud punktist, kus $h=0$ (või $k=0)$.

\section{Võrandi $\boldsymbol{x}^{5}+\boldsymbol{p} \boldsymbol{x}^{3}+\boldsymbol{q} \boldsymbol{x}^{2}+\boldsymbol{r} \boldsymbol{x}+\boldsymbol{s}=\mathbf{0}$ nomograafiline lahendamine}

7. Teisendusega $x=\sqrt[5]{\sqrt{5}} \cdot \mathrm{x}$ saadakse selle võrrandi asemele $s \mathrm{x}^{5}+p \sqrt[5]{s^{3} \mathrm{x}^{3}+q \sqrt[5]{s^{2} \mathrm{x}^{2}}+r \sqrt[5]{ } \mathrm{s} \mathrm{X}}+s=0$, mis lihtsustub liikmete ümberpaigutamisel ja avaldisega $s \mathrm{x}$ jagamisel järgmiseks:

$$
\mathrm{x}^{4}+\frac{1}{\mathrm{x}}=-\frac{p}{\sqrt{s^{2}}} \mathrm{x}^{2}-\frac{q}{\sqrt[5]{s^{3}}} \mathrm{x}-\frac{r}{\sqrt{s^{4}}},
$$

sisaldades veel ainult kolme individuaalset konstanti, mis olgu tähistatud $a, b$ ja $c$ :

$$
a=-\frac{p}{\sqrt[5]{s^{2}}}, \quad b=-\frac{q}{\sqrt{s^{3}}}, \quad c=-\frac{r}{\sqrt[5]{s^{4}}} .
$$

Võrrandi $x^{4}+\frac{1}{x}=a x^{2}+b x+c$ lahenditeks on nähtavasti joonte $y=x^{4}+\frac{1}{x}$ ja $y=a x^{2}+b x+c$ lõikepunktide abstsissid. Esimene neist joontest on kõigil juhtudel üks ja seesama ning teda tarvitseb nähtavasti ainult üks kord joonestada (joon. 8). Teine joon on parabool; kui selle võrrandis liikmed sobivalt rühmitada:

$$
\mathrm{y}=a\left(\mathrm{x}+\frac{b}{2 a}\right)^{2}+c-\frac{b^{2}}{4 a},
$$


siis selgub, et ta on kongruentne parobooliga $y=a x^{2}$ ja et tema haripunkt on $\left(-\frac{b}{2 a} ; c-\frac{b^{2}}{4 a}\right)$ ehk $\left(-\frac{q}{2 p \sqrt{s}} ; \frac{q^{2}-4 p r}{4 p s} \sqrt[5]{s}\right)$ ja tema telg on ordinaatteljega paralleelne. Järelikult tarvitseb ainult joonestada läbipaistvale lehele pere paraboole $\mathrm{y}=a \mathrm{x}^{2}$, võttes parameetri $a$ väärtused paraja tihedusega (võib piirduda positiivsete $a$ väärtustega, sest üleminek vastandarvulisele $a$ väärtusele toimub joonise pööramisega sirgnurga võrra);

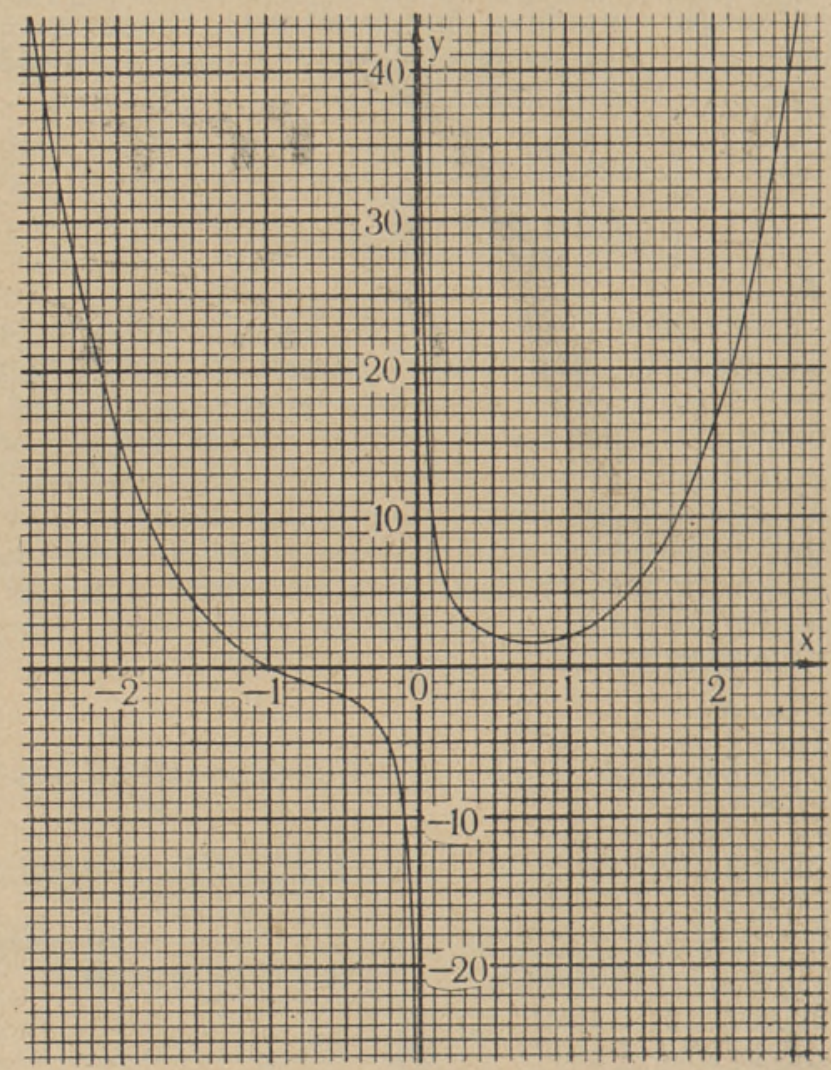

Joon. 8 .

parabooliks $\mathrm{y}=a \mathrm{x}^{2}+b \mathrm{x}+c$ joonisele 8 kandub läbipaistval lehel olev parabool $\mathrm{y}=a \mathrm{x}^{2}$ sel teel, et tema haripunkt viiakse ühtimisele punktiga $\left(-\frac{b}{2 a} ; c-\frac{b^{2}}{4 a}\right)$ ja telg seatakse ordinaatteljega paralleelseks. Selles asetuses ongi juba võimalik parabooli ja joone $y=x^{4}+\frac{1}{x}$ lõikepunkte näha ja nende abstsisse ära lugeda.

Et niisugune geomeetriline võte võrrandi lahendite leidmiseks ei nõua pärast joone $y=x^{4}+\frac{1}{x}$ ja paraboolide pere $y=a x^{2}$ joonestamist enam mingisugust uute joonte tõmbamist üksikvõrrandite individuaalandmete järgi, siis kuulub see võte nomograafiliste hulka. Vastav nomogramm koosneb kahest teineteise peal asetsevast lehest, mida tuleb teineteise suhtes nihutada. Alumine leht (joon. 8) on varustatud koordinaadi- 
vơrguga, ülemine leht on läbipaistev (tselluloidplaat vōi lihtsalt pergamiinpaber, mis oleks võinud siinkohal lahtise lehena kaasa antud olla) ja sellele on joonestatud pere paraboole. Olgu tähendatud, et joonte parema lõikumise saavutamiseks ja lõikepunktide abstsisside lugemistäpsuse tõstmiseks on kohane võtta abstsisside mõõtühik ordinaatide omast kümme korda suurem. Veel võib märkida, et kõverat $y=x^{4}+\frac{1}{x}$ ei tarvitse joonestada kuigi suures ulatuses, sest kõvera need punktid, mille kaugus abstsissteljest on juba paarsada ühikut, on küllalt hästi asendatavad kas joone $y=x^{4}$ või joone $y=\frac{1}{x}$ vastavate punktidega. Seega on praktiliselt hõlpsasti saavutatav niisugune olukord, et kui võrrandi lahendamiseks vajalikud lõikepunktid satuvad valmistatud nomogrammi piiridest välja, siis on nende abstsissid leitavad juba lihtsamate vorrrandite - kas $\mathrm{x}^{4}=a \mathrm{x}^{2}+b \mathrm{x}+c$ või $\frac{1}{\mathrm{x}}=a \mathrm{x}^{2}+b \mathrm{x}+c$ - lahendamise teel umbes sama ligikaudsusega.

8. Võrrandi $x^{5}+p x^{3}+q x^{2}+r x+s=0$ lahendamiseks on võimalik ka teisiti nomogramme valmistada. Kui võtta nagu ennegi uus otsitav $\mathrm{x}$ nii, et $x=\sqrt[5]{ } \sqrt{s} \mathrm{x}$, siis saadakse võrrand

$$
\mathrm{x}^{5}+A \mathrm{x}^{3}+B \mathrm{x}^{2}+C \mathrm{x}+1=0,
$$

milles nähtavasti nüüd

$$
A=\frac{p}{\sqrt[5]{s^{2}}}, \quad B=\frac{q}{\sqrt{s^{3}}} \quad \text { ja } \quad C=\frac{r}{\sqrt{s^{4}}} .
$$

Sellele võrrandile võib hakata valmistama skaaladest koosnevat nomogrammi, moodustades vasaku skaala punktidest $(0 ; A)$ ja parempoolse punktidest $(1 ; C)$. Keskel asetsev skaala moodustuks siis igal etteantud $B$ väärtusel järgmistest punktidest:

$$
\left(\frac{1}{1+x^{2}} ;-\frac{1+x^{5}}{x\left(1+x^{2}\right)}-\frac{B x}{1+x^{2}}\right) .
$$

See aga tähendab, et on vaja joonestada mitte üks niisugune skaala, vaid hulk skaalasid ja võtta selleks $B$ väärtused paraja tihedusega (et oleks võimalik õigesti ette kujutada ja kasutada ka vahepealsetele $B$ väärtustele vastavaid skaalasid, mida joonestatud pole). Asjaolu, et kõigi kõverate skaalade punktidel on abstsiss $\frac{1}{1+x^{2}}$, olenematult suurusest $B$, võimaldab nende skaalade (x-skaalade) lugemiseks kasutada püstsirgeid, mille juurde on kirjutatud vastavad suuruse $\mathrm{x}$ väärtused.

Otstarbekohane on jaotada kirjeldatud nomogramm kaheks osaks (joon. 9 ja 10) - üks positiivsete ja teine negatiivsete lahendite leidmiseks. Kummagi osa kasutamisviis on jälle seesama, mis on selgitatud juba joonise 2 puhul; ainus erinevus on nüüd selles, et keskel olevatest skaaladest tuleb võtta see, mis kuulub antud $B$ väärtusele.

\section{Nomogrammide võrdlus}

9. Nomograafiliste võtete kasutaja esitab nomogrammile õigustatult järgmised nổuded: 1) nomogramm olgu hõlpsasti valmistatav, 2) nomogramm võimaldagu antud tüüpi ülesandeid lahendada igasugusel andmete valikul, 3) nomogrammi kasutamine piirdugu võimalikult vähese abiarvutusega. Kui nende nõuete seisukohalt võrrelda neljandaastmelise võrrandi 


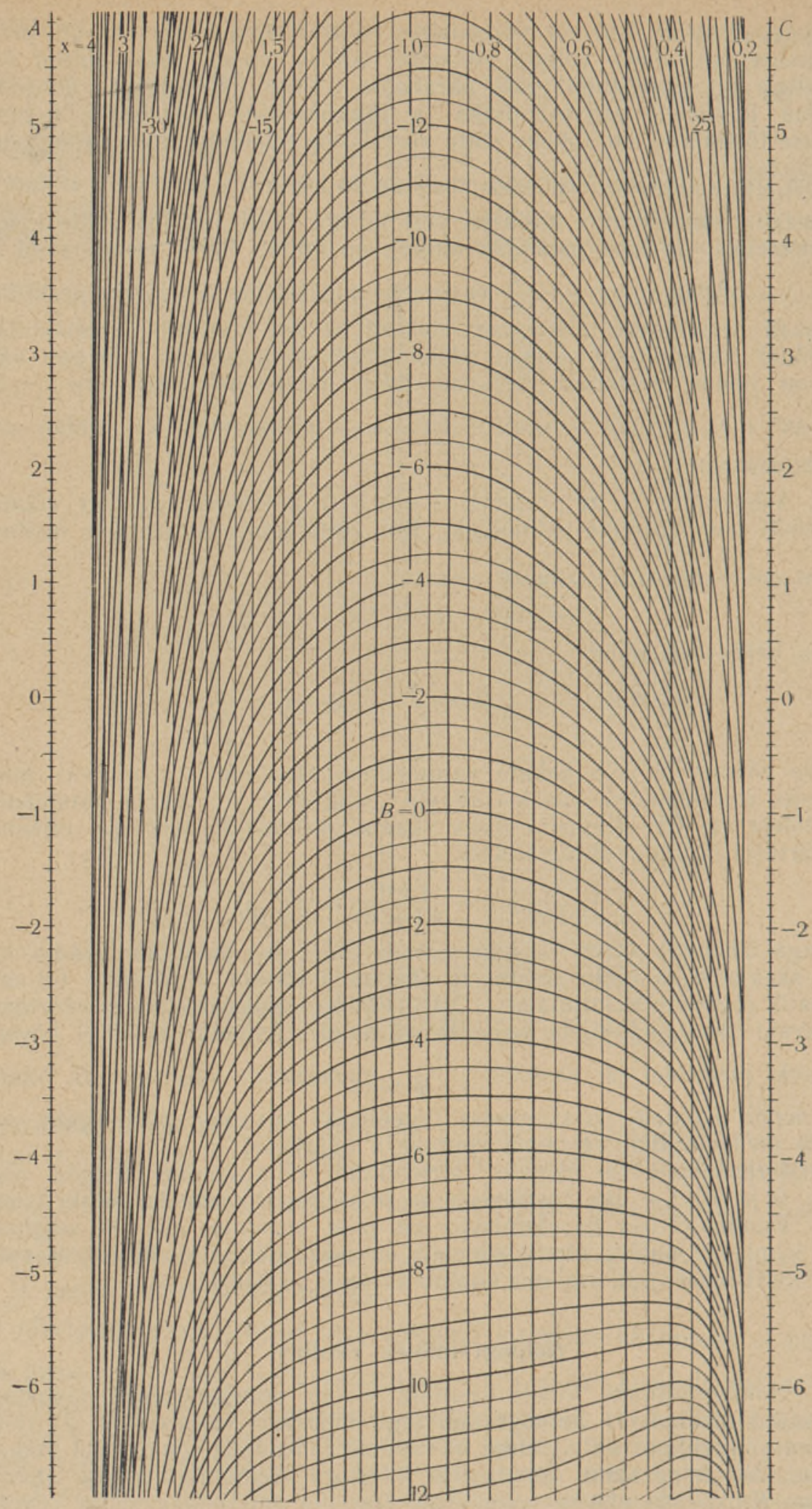

Joon. 9. 


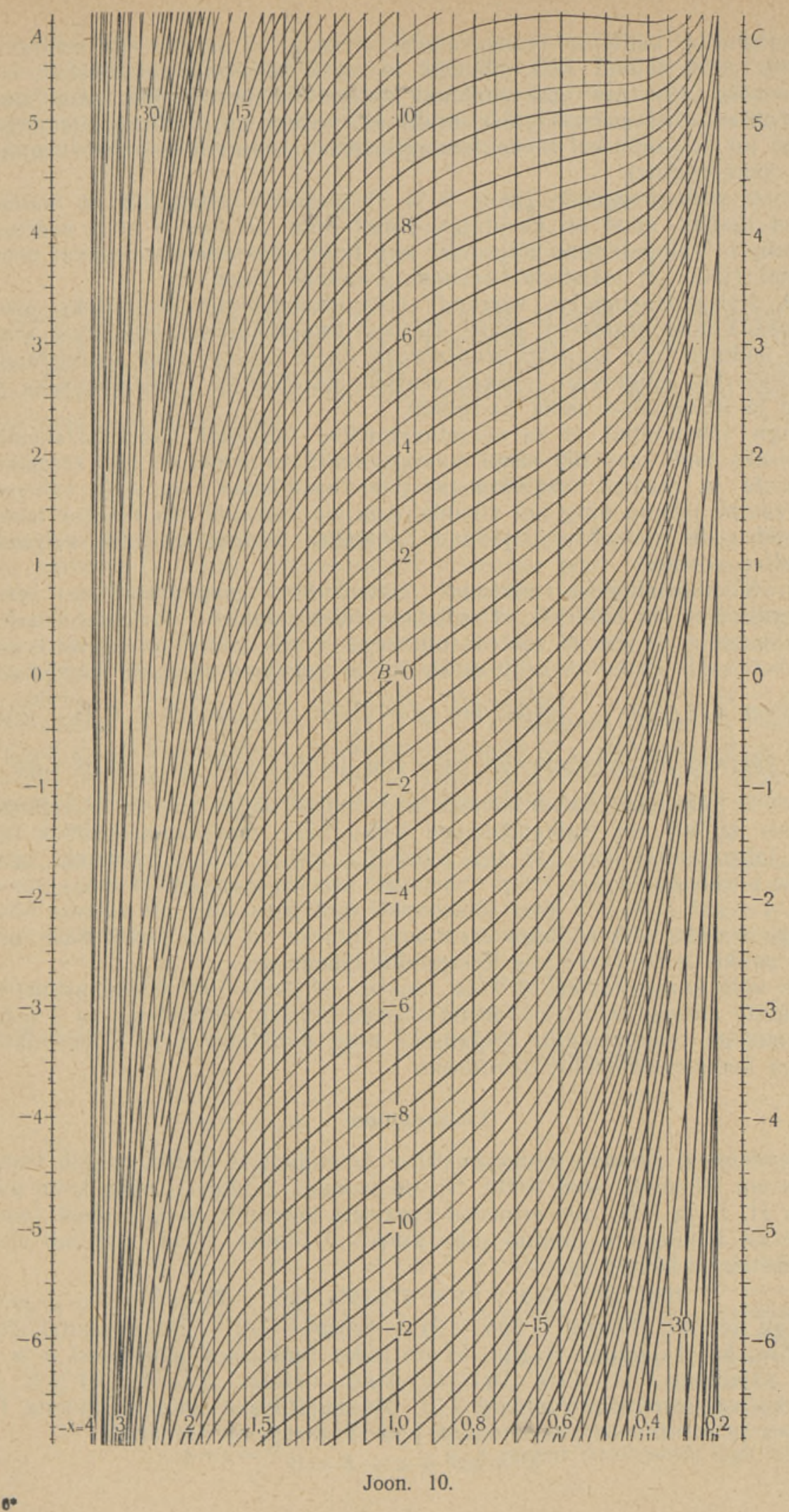


reaallahendite leidmise nomogramme (joon. 1, 2 ja 3), siis selgub, et esimene - neist täidab kõik nổuded: ta on ülihõlpsasti valmistatav, kord valmistatud suuruses igal andmete valikul kasutatav ega nõua kuigi palju abiarvutusi (ainsaks tõsisemaks arvutuseks on raadiuse leidmine ja ka see on hõlpsam kui teiste nomogrammide kasutamise puhul kuupjuurega opereerimine).

Teiste nomogrammide (joon. 2 ja 3 ) oluliseks puuduseks on muidugi see, et igaüks neist on kasutatav ainult oma kindlas $a$ ja $b$ väärtuste piirkonnas. Valmistamise hõlpsuselt aga tuleb skaaladest koosnevat nomogrammi (joon. 2) eelistada võrknomogrammile (joon. 3).

10. Neljandaastmelise võrrandi komplekslahendite leidmiseks piisab reaalosade nomogrammist (joon. 4), sest imaginaarosad on pärast reaalosade leidmist juba kergesti arvutatavad. Selle nomogrammi valmistamine on kerge, kui kõigepealt tehakse sealsete paraboolide joonestamiseks erilekaal ja märgitakse sellel haripunkt.

Olgu tähendatud, et ka viiendaastmelise võrrandi komplekslahendite leidmiseks saab kasutada sama nomogrammi: teatavasti on igal (reaalsete kordajate ja reaalse vabaliikmega) paarituastmelisel võrrandil vähemalt üks reaalne lahend ning kui viiendaastmelise võrrandi üks reaalne lahend on teada, siis saadakse ülejäänud lahendite leidmiseks juba neljandaastmeline vorrrand.

11. Viiendaastmelise võrrandi lahendamise nomograafiliste võtete võrdlemisel ei jää kahtlust, et eelistada tuleb punktis 7 kirjeldatud võtet. Peamine eelis on see, et sobiva suurusega joonis, millel on sobivalt valitud abstsisside ühiku ja ordinaatide ühiku vahekord ning on joonestatud pōhikõver $\mathrm{y}=\mathrm{x}^{4}+\frac{1}{\mathrm{x}}$, võimaldab praktiliselt igasugustel $a, b$ ja $c$ väärtustel võrrandi üht reaallahendit leida: kui joonte $y=x^{4}+\frac{1}{x}$ ja $y=a x^{2}+$ $+b x+c$ lõikepunkt satub joonise piirkonnast välja, siis on lõikepunkti abstsiss küllalt hea ligikaudsusega leitav juba madalamaastmelise võrrandi lahendamise teel; kui aga joone $y=a x^{2}+b x+c$ haripunkt satub joonise piirkonnast välja, kuigi lõikepunkt asetseb joonise piirkonnas, siis on joone $\mathrm{y}=a \mathrm{x}^{2}+b \mathrm{x}+c$ kaar lõikepunkti ümbruses juba nii väikese kõverusega, et teda võib kõõluga asendada, milleks on vaja ainult kaks selle joone punkti leida (arvatava löikepunkti lähedusse).

Nii võib konstateerida, et kõik vajalik neljanda- ja viiendaastmeliste võrrandite nomograafiliseks lahendamiseks piirdub punktides 1 ja 7 esitatud võtetega reaallahendite leidmiseks ning punktides 4 ja 5 kirjeldatud võttega komplekslahendite saamiseks.

\section{Lisatulemusi}

12. Mōnest võrrandi nomograafilise lahendamise võttest selgub teatav kriteerium lahendite arvu kohta. Nii on joonisel 3 selgesti näha kolm piirkonda. (I, II ja III), mis erinevad reaalsete lahendite arvu poolest (nagu sellele on tähelepanu juhitud juba punkti 3 lõpus). Neid piirkondi eraldab üksteisest kôverjoon

$$
16 a b\left(a^{3}-8 a b+9\right)+4\left(64 b^{3}-a^{3}\right)-27=0 .
$$

Olgu avaldis $16 a b\left(a^{3}-8 a b+9\right)+4\left(64 b^{3}-a^{3}\right)-27$ tähistatud lühidalt $T(a, b)$. Asjaolust, et $T(a, b)$ on pidev funktsioon suurustest $a$ ja $b$, koos asjaoluga, et $T(0,0)<0$, kuid näiteks $T(-2,0)>0$ ja $T(0,1)>0$, järeldub avaldise $T(a, b)$ negatiivsus kogu piirkonna III ulatuses ja positiivsus piirkondades I ja II. Seega on võrrandil

$$
\mathrm{x}^{4}+a \mathrm{x}^{2}+\mathrm{x}+b=0
$$


kaks reaalset lahendit, kui $a$ ja $b$ täidavad tingimust $T(a, b)<0$, ja neli reaalset lahendit või polegi reaalset lahendit, kui $T(a, b)>0$. Mõlema viimatinimetatud juhtumi teineteisest eraldamiseks läheb vaja täiendavaid tingimusi andmete $a$ ja $b$ kohta. Täiendavate tingimuste saamiseks võib lähtuda piirkondi eraldava kõverjoone võrrandipaarist

$$
\left\{\begin{array} { l } 
{ \mathrm { x } ^ { 4 } + a \mathrm { x } ^ { 2 } + \mathrm { x } + b = 0 } \\
{ 4 \mathrm { x } ^ { 3 } + 2 a \mathrm { x } + 1 = 0 }
\end{array} \text { ehk } \left\{\begin{array}{l}
a=-2 \mathrm{x}^{2}-\frac{1}{2 \mathrm{x}} \\
b=\mathrm{x}^{4}-\frac{\mathrm{x}}{2}
\end{array}\right.\right.
$$

ja tähele panna, et piirkondi I ja III eraldab teineteisest see kõverjoone osa, kus $x>0$, kuna piirkondi II ja III eraldab see osa, kus $x<0$. Võttes nüüd ühe niisuguse punkti, kus $\mathrm{x}=t$, ja teise, kus $\mathrm{x}=-t$, saadakse nendevahelise lổigu poolituspunkt alati piirkonnas III; säärastest poolituspunktidest moodustub joon

$$
\left\{\begin{array} { l } 
{ a = - 2 t ^ { 2 } } \\
{ b = t ^ { 4 } }
\end{array} \quad \text { ehk } \quad \left\{\begin{array}{l}
a^{2}=4 b \\
a<0 .
\end{array}\right.\right.
$$

Arvesse võttes veel seda, et piirkond I kuulub alale, kus $a<0$ ja $a^{2}>4 b$, kuid piirkond II ulatub ordinaatteljest mõlemale poole (ühes osas $a \geqslant 0$, teises osas $a<0$ ja $\left.a^{2}<4 b\right)$, saab konstateerida järgmist: võrrandil $x^{4}+a x^{2}+x+b=0$ on neli reaalset lahendit, kui $T(a, b)>0$ ning seejuures $a<0$ ja $a^{2}>4 b$; võrrandil ei ole reaalset lahendit, kui $T(a, b)>0$ ning seejuures kas $a \geqslant 0$ või $a<0$ ja $a^{2}<4 b$.

Leitud tingimusi saab üle kanda võrrandile $x^{4}+p x^{2}+q x+r=0$, avaldades $a$ ja $b$ andmete $p, q$ ja $r$ abil; mõningaid täiendusi lisandub juhtumi $q=0$ käsitlemisest (vastavat võrrandit $x^{4}+p x^{2}+r=0$ on lihtne otseselt lahendada). Sel teel saadud tulemusi esitab järgmine tabel, kus avaldis $16 p r\left(p^{3}+9 q^{2}-8 p r\right)+4\left(64 r^{3}-p^{3} q^{2}\right)-27 q^{4}$ on tähistatud

\begin{tabular}{|c|c|c|}
\hline 2 & Tingimused & Lahendite arv \\
\hline \multicolumn{2}{|l|}{$U(p, q, r)<0$} & 2 reaalset ja 2 kompleksset lahendit \\
\hline \multirow{3}{*}{$U(p, q, r)>0$} & $p<0, \quad p^{2}>4 r$ & 4 reaallahendit \\
\hline & $p<0, p^{2}<4 r$ & \multirow{2}{*}{4 komplekslahendit } \\
\hline & $p \geqslant 0$ & \\
\hline \multirow{8}{*}{$U(p, q, r)=0$} & $p \geqslant 0, q \neq 0$ & \multirow{3}{*}{$\begin{array}{l}2 \text { vōrdset reaalset ja } 2 \text { kompleksset } \\
\text { lahendit }\end{array}$} \\
\hline & $p<0, p^{2}<4 r$ & \\
\hline & $p>0, q=r=0$ & \\
\hline & $8 p^{3}<-27 q^{2} \not \neq 0, p^{2}>4 r$ & 2 võrdset ja 2 erinevat reaallahendit \\
\hline & $8 p^{3}=-27 q^{2}, r<0$ & 3 vördset ja 1 erinev reaallahend \\
\hline & $p<0, q=0$ & 2 paari võrdseid reaallahendeid \\
\hline & $p>0, q=0, r \neq 0$ & 2 paari võrdseid komplekslahendeid \\
\hline & $p=q=0$ & 4 võrdset reaallahendit (iga lahend 0 ) \\
\hline
\end{tabular}
$U(p, q, r)$. 
13. Võrrandi $x^{5}+p x^{3}+q x^{2}+r x+s=0$ reaalsete lahendite arvu kohta on võimalik teha mõningaid järeldusi nomograafilisest lahendamisvõttest, mis on esitatud punktis 7 . Selleks tuleb kasutada joone $y=x^{4}+\frac{1}{x}$ järgmisi omadusi:

1) joone parempoolses osas on abstsissteljele lähimal punkt $(\sqrt[5]{0,25} ; 1,25 \sqrt[5]{4})$ ja seetõttu iga parabool $\mathrm{y}=a \mathrm{x}^{2}+b \mathrm{x}+c$, millel $a$ on positiivne ja haripunkti ordinaat ületab arvu $1,25 \sqrt[5]{4}$, lõikab joont $\mathrm{y}=\mathrm{x}^{4}+\frac{1}{\mathrm{x}}$ vähemalt kolm korda;

2) kui $a<0$ ja parabooli haripunkt asetseb piirkonnas, kus $x>0$ ja $y>x^{4}+\frac{1}{x}$, siis parabool lõikab joont $y=x^{4}+\frac{1}{x}$ täpselt kolm korda;

3) parabool $\mathrm{y}=a \mathrm{x}^{2}+b \mathrm{x}+c$, millel $a$ on negatiivne, haripunkti

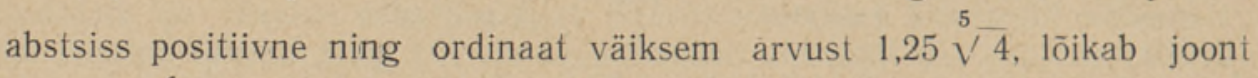
$y=x^{4}+\frac{1}{x}$ üksainus kord;

4) joone $y=x^{4}+\frac{1}{x}$ käänupunkt on $\left(-\sqrt[5]{\frac{1}{6}} ;-\frac{5}{6} \sqrt[5]{6}\right)$ ning kōigist paraboolidest, mis teda käänupunktis puudutavad, on ainult ühel haripunkti ordinaat $1,25 \sqrt[5]{4}$, kuna haripunkti abstsissiks osutub $-\sqrt[5]{\frac{16}{3}}-\frac{1}{2} \sqrt[5]{ }^{27}$; kui haripunkti abstsiss võtta sellest väiksem (ja ordinaat endine) ning $a<0$, siis parabool lõikab joont $y=x^{4}+\frac{1}{x}$ üksainus kord.

Võrrandi $\mathrm{x}^{4}+\frac{1}{\mathrm{x}}=a \mathrm{x}^{2}+b \mathrm{x}+c$ lahenditeks on joonte $\mathrm{y}=\mathrm{x}^{4}+\frac{1}{\mathrm{x}}$ ja $\mathrm{y}=a \mathrm{x}^{2}+b \mathrm{x}+c$ lõikepunktide abstsissid; pealegi on tal lahendeid niisama palju kui esialgsel võrrandil $x^{5}+p x^{3}+q x^{2}+r x+s=0$, millest ta teisendamisel tekkis. Seega saab võrrandi $x^{5}+p x^{3}+q x^{2}+r x+s=0$ reaalsete lahendite arvu kohta teha niisugused järeldused:

1) kui $p<0$ ja $q^{2}<p\left(4 r+5 \sqrt[5]{4 s^{4}}\right)$, siis on lahendeid vähemalt kolm;

2) kui $p>0$, qs $<0$ ja $\left(\frac{q}{p}\right)^{4}+16 r<\frac{4}{p q}\left(q^{3}+8 p^{2} s\right)$, siis on lahendeid täpselt kolm;

3) kui $p>0, q s<0$ ja $q^{2}>p\left(4 r+5 \sqrt[5]{4 s^{4}}\right)$, siis on üksainus lahend; 4) kui $0<p<\frac{q}{\sqrt[5]{81}+2 \sqrt[5]{16}} \sqrt{\frac{3}{s}}$ ja $q^{2}>p\left(4 r+5 \sqrt[5]{4 s^{4}}\right)$, siis on jallegi üksainus lahend. 
1. Е. Я нке и Ф. Эмде, Таблицы функций с формулами и кривыми, Гостехиздат, М.-Л., 1949, стр. 44-47.

2. A. $\mathrm{Hum}$ a 1, Ruutvồrrandi geomeetriline lahendamine, Tallinna Polütehnilise Instituudi Toimetised, Seeria A nr. 27, RK „Teaduslik Kirjandus”, Tartu, 1947.

3. А. К. С уш ке в и ч, Основы высшей алгебры, 3-е издание, Гостехиздат, М.-Л., 1937, crp. 102 .

4. Ernst Lindelöf, Einführung in die höhere Analysis, deutsch bearbeitet von E. Ullrich, Verlag B. G. Teubner, 1934, S. 20.

5. М. В. Пен тков ски й, Номография, Гостехиздат, М.-Л., 1949, стр. 80.

\title{
О НОМОГРАФИЧЕСКОМ РЕШЕНИИ АЛГЕБРАИЧЕСКИХ УРАВНЕНИЙ
}

\author{
А. К. ХУМАЛ, \\ действительный член Академии наук Эстонской ССР \\ Резюме
}

При решении алгебраических уравнений применение номографических способов оправдывает себя лишь начиная с уравнения четвертой степени, так как для кубического уравнения имеется еще практически приемлемый численный способ решения с помощью специальной таблицы ( $\left.{ }^{1}\right)$.

Простейшим номографическим способом решения уравнения четвертой степени

$$
x^{4}+p x^{2}+q x+r=0
$$

является следующий $\left({ }^{4}\right)$ : 'вводится новое неизвестное $y=x^{2}$, так что данное уравнение четвертой степени переходит в уравнение окружности $x^{2}+y^{2}+q x+(p-1) y+r=0$. Решениями уравнения четвертой степени являются абсциссы точек пересечения параболы $y=x^{2}$ и окружности с центром $\left(-\frac{q}{2}, \frac{1-p}{2}\right)$ и радиусом $\sqrt{\left(\frac{q}{2}\right)^{2}+\left(\frac{1-p}{2}\right)^{2}-r}$. Номограммой служит вычерченная в обычной координатной сети парабола (фиг. 1); а скружности (для каждого уравнения особая окружность) не вычерчиваются, так как упомянутые точки пересечения можно найти острнем циркуля, если центр и радиус окружности известны.

По сравнению с номограммой из выравненных точек (фиг. 2) и сетчатой номограммой (фиг. 3) вышеизложенный способ заслуживает предпочтения потому, что уравнение $x^{4}+p x^{2}+q x+r=0$ при любых значениях $p, q, r$ можно приспособить к размерам заранее изготовленной номограммы (фиг. 1) простым преобразованием $x=c x$; подходящее для этого значение $c$ видно из полученного уравнения

$$
\mathrm{x}^{4}+\frac{p}{c^{2}} \mathrm{x}^{2}+\frac{q}{c^{3}} \mathrm{x}+\frac{r}{c^{4}}=0 .
$$

Для нахождения комплексных решений уравнения четвертой степени $\mathrm{x}^{4}+a \mathrm{x}^{2}+\mathrm{x}+b=0$ можно построить номограмму исходя из того, что эти решения

удовлетворяют уравнению $\left(\mathrm{x}^{2}-2 m \mathrm{x}+n\right)\left(\mathrm{x}^{2}+2 m \mathrm{x}+\frac{b}{n}\right)=0$ при $n=m^{2}+h^{2}$; отсюда

$$
4 b=\left(a+4 m^{2}\right)^{2}-\frac{1}{4 m^{-}},
$$


что дает возможность построения сетчатой номограммы для отыскания $m$ (фиг. 4). Значения $h$ и $k$ можно затем вычислить по формулам

$$
h=\sqrt{\frac{a}{2}+m^{2}+\frac{1}{4 m}}, \quad k=\sqrt{\frac{a}{2}+m^{2}-\frac{1}{4 m}}
$$

(или же воспользоваться соответствующими номограммами из выравненных точек, фиг, 5 и 6).

Уравнение $x^{5}+p x^{3}+q x^{2}+r x+s=0$ можно подстановкой $x=\sqrt[5]{s} \cdot \mathrm{x}$ превратить в

$$
\mathrm{x}^{4}+\frac{1}{\mathrm{x}}=a \mathrm{x}^{2}+b \mathrm{x}+c
$$

решениями которого являются абсциссы точек пересечения кривых $\mathrm{y}=\mathrm{x}^{4}+\frac{1}{\mathrm{x}}$ и $\mathrm{y}=a \mathrm{x}^{2}+b \mathrm{x}+c$. Последняя получается путем параллельного переноса параболы $\mathrm{y}=a \mathrm{x}^{2}$ так, чтобы вершина ее совпала с точкой $\left(-\frac{b}{2 a}, c-\frac{b^{2}}{4 a}\right)$. Таким образом, номограмма для решения уравнений пятой степени состоит из двух чертежей: 1) кривая $\mathrm{y}=\mathrm{x}^{4}+\frac{1}{\mathrm{x}}$, вычерченная в координатной сети (фиг. 8), 2) семейство парабол $\mathrm{y}=a \mathrm{x}^{2}$ на прозрачной пластинке или кальке ( $a$ является параметром семейства) .

Если для уравнения $\mathrm{x}^{5}+A \mathrm{x}^{3}+B \mathrm{x}^{2}+C \mathrm{x}+1=0$ построить номограмму из выравненных точек со шкалами $(0, A)$ и $(1, C)$, то $B$ остается параметром семейства х-шкал (фиг. 9 и 10).

Из формы кривой $\mathrm{y}=\mathrm{x}^{4}+\frac{1}{\mathrm{x}}$ (фиг. 8) можно сделать некоторые выводы о количестве точек пересечения ее с разными параболами. Эти выводы, повидимому, касаются числа действительных решений уравнения пятой степени $x^{5}+p x^{3}+q x^{2}+r x+s=0$ и, в соответствующей формулировке, гласят:

1) если $p<0$ и $q^{2}<p\left(4 r+5 \sqrt[5]{4 s^{4}}\right)$, то решений не меньше трех;

2) если $p>0$, $q s<0$ и $\left(\frac{q}{p}\right)^{4}+16 r<\frac{4}{p q}\left(q^{3}+8 p^{2} s\right)$, то решений точно 3 ;

3) если $p>0, q s<0$ и $q^{2}>p\left(4 r+5 \sqrt[5]{4 s^{4}}\right)$, то имеется лишь одно решение;

4) если $0<p<\frac{q}{\sqrt[5]{81}+2 \sqrt{16}} \sqrt[5]{\frac{5}{s}}$ и $q^{2}>p\left(4 r+5 \sqrt[5]{4 s^{4}}\right)$, то решение также единственное. 